\title{
Cross-cultural adaptation and validation of the Brazilian version of the Beliefs about Emotions Scale
}

\author{
Adaptação transcultural e validação da versão brasileira da Escala de Crenças \\ sobre Emoções
}

\author{
Daniel C. Mograbi, ${ }^{1,2}$ Pamela Indelli, ${ }^{1}$ Caio A. Lage,${ }^{1}$ Vitória Tebyriça, ${ }^{1}$ \\ Jesus Landeira-Fernandez, ${ }^{1}$ Katharine A. Rimes ${ }^{2}$
}

\begin{abstract}
Introduction: Beliefs about the unacceptability of expression and experience of emotion are present in the general population but seem to be more prevalent in patients with a number of health conditions. Such beliefs, which may be viewed as a form of perfectionism about emotions, may have a deleterious effect on symptomatology as well as on treatment adherence and outcome. Nevertheless, few questionnaires have been developed to measure such beliefs about emotions, and no instrument has been validated in a developing country. The current study adapted and validated the Beliefs about Emotions Scale in a Brazilian sample.

Methods: The adaptation procedure included translation, backtranslation and analysis of the content, with the final Brazilian Portuguese version of the scale being tested online in a sample of 645 participants. Internal consistency of the scale was very high and results of a principal axis factoring analysis indicated a two-factor solution.

Results: Respondents with high fatigue levels showed more perfectionist beliefs, and the scale correlated positively with questionnaires measuring anxiety, depression and fear of negative evaluation, confirming cross-cultural associations reported before. Finally, men, non-Caucasians and participants with lower educational achievement gave greater endorsement to such beliefs than women, Caucasian individuals and participants with higher educational level.

Conclusions: The study confirms previous clinical findings reported in the literature, but indicates novel associations with demographic variables. The latter may reflect cultural differences related to beliefs about emotions in Brazil.
\end{abstract}

Keywords: Beliefs, emotion, emotional regulation, perfectionism, validation.

\section{Resumo}

Introdução: Crenças sobre a inaceitabilidade da expressão e experiência de emoção estão presentes na população em geral, mas parecem ser mais prevalentes em pacientes com uma série de problemas de saúde. Tais crenças, que podem ser vistas como uma forma de perfeccionismo sobre as emoções, podem ter um efeito deletério na sintomatologia, bem como na adesão ao tratamento e nos seus resultados. No entanto, poucos questionários foram desenvolvidos para medir tais crenças sobre emoções, e nenhum instrumento foi validado em um país em desenvolvimento. O presente estudo adaptou e validou a Escala de Crenças sobre Emoções (Beliefs about Emotions Scale) em uma amostra brasileira.

Métodos: O procedimento de adaptação incluiu tradução, retrotradução e análise do conteúdo, com a versão final brasileira da escala sendo testada online em uma amostra de 645 participantes. A consistência interna da escala foi muito alta e os resultados da análise fatorial de eixo principal indicaram uma solução de dois fatores.

Resultados: Os respondentes com altos níveis de fadiga mostraram crenças mais perfeccionistas, e a escala se correlacionou positivamente com questionários medindo ansiedade, depressão e medo de avaliação negativa, confirmando associações transculturais relatadas anteriormente. Finalmente, homens, não caucasianos e participantes com baixo nível de escolaridade endossaram mais tais crenças do que mulheres, indivíduos caucasianos e participantes com maior nível de escolaridade.

Conclusões: $O$ estudo confirma achados clínicos anteriores relatados na literatura, mas indica novas associações com variáveis demográficas. O último pode refletir diferenças culturais relacionadas às crenças sobre emoções no Brasil.

Descritores: Crenças, emoção, regulação emocional, perfeccionismo, validação.

\footnotetext{
${ }^{1}$ Departamento de Psicologia, Pontifícia Universidade Católica do Rio de Janeiro (PUC-Rio), Rio de Janeiro, RJ, Brazil. ${ }^{2}$ Department of Psychology, Institute of Psychiatry, Psychology and Neuroscience, King's College London, London, UK. Submitted May 31 2017, accepted for publication Aug 282017.

Suggested citation: Mograbi DC, Indelli P, Lage CA, Tebyriça V, Landeira-Fernandez J, Rimes KA. Cross-cultural adaptation and validation of the Brazilian version of the Beliefs about Emotions Scale. Trends Psychiatry Psychother. 2018;40(1):21-28. http://dx.doi.org/10.1590/2237-6089-2017-0064
} 


\section{Introduction}

A number of health conditions are marked by the presence of beliefs about the unacceptability of the expression and experience of negative emotions, including chronic fatigue syndrome (CFS), ${ }^{1}$ eating disorders, ${ }^{2}$ and major depression. ${ }^{3,4}$ In addition, according to cognitive behavioral models, deleterious beliefs on emotions contribute to the etiology and maintenance of a range of other health conditions, such as hypertension, ${ }^{5}$ irritable bowel syndrome, ${ }^{6,7}$ and impulse control disorders. ${ }^{8,9}$ Beliefs about emotions also play a central role in the maintenance of clinical problems, being associated with poor prognosis and low efficacy of treatment attempts. ${ }^{2}$ Identifying unhelpful beliefs about emotions may help with reducing maladaptive coping and compensatory strategies, ${ }^{10}$ leading to improved forms of treatment.

Despite the relevance of this theme, few attempts have been made to systematically measure beliefs about emotions. ${ }^{11,12} \mathrm{An}$ initial attempt was made by Tamir et al., ${ }^{13}$ who measured beliefs about the malleability and control over emotions using a brief four-item questionnaire. A full questionnaire, the Beliefs about Emotions Scale (BES), was later developed by Rimes \& Chalder. ${ }^{11}$ The BES focuses on beliefs about the experience and expression of negative thoughts and feelings, based on cognitive models that suggest that beliefs about the unacceptability of negative emotions may lead to reduced expression of feelings and help-seeking behavior, resulting in increases in mental and physical symptoms. ${ }^{6}$ More recently, the Emotion and Regulation Beliefs Scale (ERBS) was developed, ${ }^{12}$ but, in addition to being considerably longer, it also measures beliefs about the construct of emotion in a broader sense, without emphasizing clinical aspects as much as the BES.

It is likely that these beliefs will vary according to context and cultural values. Cross-cultural studies on emotion identified differences in a number of features, including, for example, display rules, ${ }^{14,15}$ emotional meaning, ${ }^{16}$ attitudes towards pain and beliefs about emotional residue. ${ }^{17-19}$ Nevertheless, this has not been explored in relation to beliefs about emotions, a main reason being that no instrument measuring this aspect has been validated outside Anglophone countries.

The present study aims to adapt and validate the BES in a Brazilian sample. ${ }^{11}$ This will allow the exploration of how beliefs about emotions operate in other settings, also providing additional data on cultural differences in emotional processing. In addition, in agreement with previous studies, it is expected that the current study will provide further evidence that perfectionist beliefs about emotions are dysfunctional, by showing associations with higher levels of fatigue, depression, anxiety and social anxiety. Understanding the contribution of these beliefs to potentially harmful behaviors, such as emotional suppression, may have important clinical implications, impacting the way therapeutic practice occurs in different conditions and disorders.

\section{Material and methods}

\section{Scale adaptation}

The adaptation and validation of the BES followed the established methodology in this field. ${ }^{20}$ Firstly, a native Portuguese speaker fluent in English translated the scale. An expert panel consisting of two psychologists and one psychiatrist then discussed if the wording was appropriate and evaluated semantic and conceptual equivalence, leading to a consensus on the final items. The scale was then back-translated into English and compared to the original scale. During this procedure, the author of the original scale (K.A.R.) reviewed the back-translated version and established that there was no loss of meaning during the translation process. Final adjustments were made and the scale was again assessed by the expert panel, leading to the final validated version (see Appendix 1).

\section{Participants}

The sample of this study comprised 645 participants recruited via electronic advertisements on social networks and e-mails. Sociodemographic and clinical characteristics of the sample are described in Table 1. The full sample ( $n=645$ ) completed questionnaires of anxiety, depression and beliefs about emotion, with a subsample ( $n=283$ ) also providing data on fatigue and fear of negative evaluation (below).

\section{Measures}

Generalized Anxiety Disorder (GAD-7)

The GAD-7 is a 7-item questionnaire used as a screening tool and severity measure for patients with generalized anxiety disorder. It also has good psychometric properties to identify panic disorder, social anxiety disorder, and post-traumatic stress disorder. ${ }^{21}$ Each of the items matches the original structure of the diagnostic criteria of the Diagnostic and Statistical Manual of Mental Disorders, 4th edition, Text Revision (DSM-IVTR), with scoring being done through a 4-point Likert scale ranging from not at all to nearly every day. ${ }^{22,23}$

\section{Patient Health Questionnaire (PHQ-9)}

The Patient Health Questionnaire (PHQ-9) is a 9-item questionnaire based directly on the nine DSM-IV 
diagnostic criteria for major depressive disorder. It has good psychometric properties to diagnose depression and monitor treatment response. ${ }^{24,25}$ Scoring is done using a 4-point Likert scale, ranging from not at all to nearly every day.

\section{Chalder Fatigue Questionnaire (CFQ)}

The Chalder Fatigue Questionnaire (CFQ) has been designed to measure the severity of fatigue and to screen for the presence of CFS. The 11-item questionnaire shows robust psychometric properties. Scores are attributed through a 4-point Likert scale, ranging from 0 (less than usual) to 3 (much more than usual). ${ }^{26,27}$

\section{Fear of Negative Evaluation Scale}

The Fear of Negative Evaluation Scale (FNE) was developed to measure apprehension about others' evaluations and expectation of negative evaluation. It consists of 30 true or false questions, some of which are reverse-coded. 28,29

\section{Beliefs about Emotions Scale (BES)}

The Beliefs about Emotions Scale (BES) was developed to evaluate beliefs about emotions related to unacceptability of experiencing negative emotions or the adverse consequences of expressing such feelings. ${ }^{11}$ The questionnaire consists of 12 items scored from 6 (totally agree) to 0 (totally disagree), and it has been shown to have very good reliability and validity. ${ }^{11}$

\section{Procedures}

A cross-sectional questionnaire-based design was used. Participants recruited for this study were invited to answer the questionnaires available online in the Survey Monkey platform, individually and without any restriction of time. Participants had the option of stopping the questionnaire and withdrawing from the study at any point.

\section{Data analysis}

To investigate internal consistency, Cronbach's alpha was calculated for the full scale and for the extracted factors. Convergent and discriminant validity of the scale was explored with correlations between the BES and its factors with clinical variables, such as anxiety (GAD7), depression (PHQ-9), and fear of negative evaluation (FNES); for all scales, total scores were used in the analysis. For the correlational analysis, to account for the effect of multiple testing, results were considered significant only if $\mathrm{p}<0.001$.

The Kaiser-Meyer-Olkin (KMO) test was used as a measure of sampling adequacy to carry out an exploratory factor analysis. Tabachnick \& Fidell suggested that KMO values should be equal to or above .60 in order to perform and interpret satisfactorily a factor analysis solution. ${ }^{30} \mathrm{~A}$ principal component analysis (PCA) was not used because this procedure inflates variance estimates, since it does not discriminate between shared and unique variance. ${ }^{31}$ Instead, a principal axis factoring (PAF) extraction method was used, with an oblique factor rotation employed (promax, $\delta=0$ ) because of potential correlation among the factors. Examination of screeplot, inspection of eigenvalues and parallel analysis were used to determine the number of factors. ${ }^{32}$ A Statistical Package for the Social Sciences (SPSS) syntax was used to perform the parallel analysis. ${ }^{33}$ Following Matsunaga, ${ }^{34}$ factor loadings above .40 were considered relevant.

Independent-samples $t$-tests were calculated to explore differences in BES scores between males and females, participants with and without further postschool qualifications, and Caucasian and non-Caucasian ethnicity. Finally, considering the previous relationship between CFS and beliefs about emotion, and to keep the analysis consistent with the original validation study, ${ }^{11}$ the sample was split according to the cut-off score on the CFQ (15, for Likert scoring of the scale), ${ }^{35}$ with a $t$-test investigating differences between participants with high and low fatigue.

Table 1 - Sociodemographic and clinical characteristics of participants ( $n=645$ )

\begin{tabular}{lc}
\hline Variable & Mean (SD) / range \\
\hline Age $(m v=7)$ & $34.5(14.5) / 18-78$ \\
Gender (female/male; $m v=7)$ & $493 / 185$ \\
Educational level (with/without further education; $m v=86)$ & $501 / 98$ \\
Ethnicity (Caucasian/non-Caucasian; $m v=8)$ & $463 / 214$ \\
GAD-7 $(m v=10)$ & $7.4(4.7) / 0-21$ \\
PHQ-9 $(m v=10)$ & $8.0(5.7) / 0-27$ \\
CFQ $(m v=362)$ & $13.3(6.0) / 0-31$ \\
FNES $(m v=362)$ & $16.4(7.7) / 0-30$ \\
\hline
\end{tabular}

$\mathrm{CFQ}=$ Chalder Fatigue Questionnaire; FNES = Fear of Negative Evaluation Scale; GAD-7 = Generalized Anxiety Disorder; $\mathrm{mv}=$ missing values; $\mathrm{PHQ}-9$ = Patient Health Questionnaire; $\mathrm{SD}=$ standard deviation. 


\section{Ethics}

The project was approved by the King's College London $(\mathrm{KCL})$ research ethics committee (PNM/13/1450) and by the ethics committee of the Department of Psychology at Pontifícia Universidade Católica do Rio de Janeiro (PUC-Rio; protocol 018/2014). All participants provided informed consent and the data were anonymized.

\section{Results}

The validated version of the BES showed good psychometric properties. The mean score for each BES

Table 2 - Mean scores for each BES item and total scale

\begin{tabular}{cc}
\hline Item & Mean (SD), range \\
\hline BES \#1 & $2.1(2.0), 0-6$ \\
BES \#2 & $1.8(1.7), 0-6$ \\
BES \#3 & $2.7(1.8), 0-6$ \\
BES \#4 & $4.2(1.6), 0-6$ \\
BES \#5 & $2.1(1.7), 0-6$ \\
BES \#6 & $2.1(1.7), 0-6$ \\
BES \#7 & $4.7(1.6), 0-6$ \\
BES \#8 & $2.7(2.0), 0-6$ \\
BES \#9 & $1.6(1.7), 0-6$ \\
BES \#10 & $1.5(1.8), 0-6$ \\
BES \#11 & $2.0(1.8), 0-6$ \\
BES \#12 & $4.0(1.6), 0-6$ \\
Total Score & $31.9(13.2), 0-72$ \\
\hline
\end{tabular}

BES = Beliefs about Emotions Scale; SD = standard deviation. item can be seen in Table 2. Cronbach's alpha for the full scale was very high $(a=0.86)$, indicating excellent internal consistency. ${ }^{36}$ The mean of corrected itemtotal correlation coefficients was moderate $(r=0.53)$, ranging from $r=0.68$ for item \#11 ("It would be a sign of weakness to show my emotions in public") to $r$ $=0.18$ for item \#7 ("I should not let myself give in to negative feelings"). Removal of item \#7 would lead to a marginal increase in internal consistency of the scale (a $=0.87$ ), but the improvement was considered minimal and the item was not deleted from the scale.

\section{Exploratory factor analysis}

The KMO analysis revealed a value of 0.90 , indicating very good sampling adequacy and that the correlation matrix was suitable for factor analysis. Examination of scree plot, inspection of eigenvalues and parallel analysis led to a two-factor solution which accounted for $50.9 \%$ of the variance. Results from the structure and pattern matrix were similar, with the latter being reported here because these are typically more conservative and not inflated by overlap between factors. ${ }^{37,38}$ Table 3 depicts the pattern of rotated factor loadings for this two-factor solution.

The two-factor solution of the BES-BR presented a well-defined structure, with all items having salient loadings in a single factor exclusively. There were no hyperplane items. The first factor was responsible for $40.3 \%$ of the variance with an eigenvalue of 4.8 . This factor consisted of nine items related to seeing emotions as signs of weakness and inferiority and not expressing

Table 3 - Factor loadings for the BES items

\begin{tabular}{|c|c|c|c|c|}
\hline \multirow[b]{2}{*}{ Item \# } & \multirow[b]{2}{*}{ Item } & \multicolumn{3}{|c|}{ BES Factors } \\
\hline & & $\mathbf{I}$ & II & Communalities \\
\hline 9 & To be acceptable to others, I must keep any difficulties or negative feelings to myself. & 0.77 & -0.07 & 0.56 \\
\hline 2 & If I have difficulties I should not admit them to others. & 0.76 & -0.10 & 0.52 \\
\hline 6 & If I show signs of weakness then others will reject me. & 0.69 & -0.02 & 0.46 \\
\hline 11 & It would be a sign of weakness to show my emotions in public. & 0.68 & 0.11 & 0.55 \\
\hline 5 & If I am having difficulties it is important to put on a brave face. & 0.68 & 0.03 & 0.49 \\
\hline 3 & If I lose control of my emotions in front of others, they will think less of me. & 0.62 & -0.02 & 0.40 \\
\hline 1 & It is a sign of weakness if I have miserable thoughts. & 0.58 & -0.01 & 0.34 \\
\hline 10 & It is stupid to have miserable thoughts. & 0.53 & 0.04 & 0.31 \\
\hline 8 & I should be able to cope with difficulties on my own without turning to others for support. & 0.44 & 0.24 & 0.35 \\
\hline 4 & I should be able to control my emotions. & 0.11 & 0.65 & 0.51 \\
\hline 12 & Others expect me to always be in control of my emotions. & 0.09 & 0.44 & 0.24 \\
\hline 7 & I should not let myself give in to negative feelings. & -0.06 & 0.44 & 0.14 \\
\hline \multicolumn{2}{|c|}{ Eigenvalue } & 4.8 & 1.3 & \\
\hline \multicolumn{2}{|c|}{ Variance $(\%)$} & 40.3 & 10.6 & \\
\hline \multicolumn{2}{|c|}{ Cronbach's alpha } & 0.90 & 0.53 & \\
\hline
\end{tabular}

BES = Beliefs about Emotions Scale.

Factor loadings obtained with principal axis factoring and promax rotation; loadings greater than 0.40 are presented in bold.

24 - Trends Psychiatry Psychother. 2018;40(1) 
them in front of others (items \#1, 2, 3, 5, 6, 8, 9, 10 and 11). Factor loadings were high and yielded excellent internal consistency ( $a=0.87$ ). The second factor explained $10.6 \%$ of the variance, with an eigenvalue of 1.2, and incorporated three items associated with emotional control (\#4, 7 and 12). Factor loadings were moderate, and internal consistency was acceptable to poor $(a=0.52)$.

\section{Relationship between the BES and sociodemographic variables}

There were significant differences related to gender, ethnicity and educational level on beliefs about emotions, but no relationship with age. Significant differences between male (mean $=35.3$, standard deviation $[\mathrm{SD}]=12.6$ ) and female (mean $=30.5$, SD $=13.2$ ) participants were observed in total BES scores $\left(t_{(638)}=4.10, \mathrm{p}<.001\right)$. Significant differences were also found between Caucasian (mean $=30.8$, SD $=$ 12.8) and non-Caucasian (mean $=34.7$, SD $=13.9$ ) participants $\left(t_{(640)}=2.81, \mathrm{p}=0.005\right)$. There were also significant differences according to educational level $\left(t_{(559)}=2.87, \mathrm{p}=0.004\right)$, with participants without further post-school qualifications exhibiting higher total BES scores (mean $=35.3, \mathrm{SD}=12.9$ ) than participants with higher educational achievement (mean $=30.9$, SD = 13.1). To explore these results further, analyses of covariance (ANCOVAs) were calculated including total GAD-7 and PHQ-9 scores as covariates. For gender and ethnicity, group differences in terms of total BES scores remained unchanged. Inclusion of covariates eliminated group differences related to educational level ( $p=$ $0.099)$. The correlation between total BES scores and age was not significant $(r=-0.01, \mathrm{p}=0.763)$.

\section{Relationship between the BES and clinical variables}

Correlational analysis indicated positive weak relationships between beliefs and anxiety, depression and fear of negative evaluation; results can be seen in Table 4. Total BES scores showed significant weak correlations with total scores on FNES, PHQ-9 and GAD7 ( $p<0.001$ in all cases). Similar correlations were observed for the first factor of the BES ("Emotions and their expression as a weakness"), but no significant correlations were found for the second factor ("Selfcontrol"). A very strong correlation was found between total scores and factor 1 , with moderate correlations of factor 2 with total BES scores and factor 1 .

Fatigue also showed an association with beliefs about emotions. Comparing BES scores of subsamples with high ( mean $=36.7, \mathrm{SD}=13.4$ ) and low fatigue (mean $=33.2, \mathrm{SD}=14.0$ ) indicated significant differences between these groups $\left(t_{(281)}=2.08, \mathrm{p}=0.038\right)$. Using bimodal scoring for the CFQ and the cut-off indicated in Cho et al. ${ }^{27}$ and Chalder et al., ${ }^{26}$ a similar result was found $\left(t_{(281)}=3.15, \mathrm{p}=0.002\right)$, with higher BES scores for participants with high fatigue (mean $=37.2, \mathrm{SD}=$ 13.9 ) in comparison to those with low fatigue (mean = $32.1, \mathrm{SD}=13.4)$.

\section{Discussion}

The analysis indicated excellent internal consistency for the validated version ( $a=0.88$ ), comparable to that of the original scale $(a=0.91) .{ }^{11}$ Item-total correlations were moderate and the item with the weakest correlation was the same as in the original study. A two-factor solution, with items loading exclusively on one of the factors, was found: the first factor accounted for most of the variance and was related to considering emotions and their expressions as signs of weakness; the second factor accounted for considerably less variance and was linked to emotional self-control. This is in disagreement with the study by Rimes \& Chalder, ${ }^{11}$ which indicated that the BES is unidimensional, and may reflect cultural differences. For example, it is possible that self-control is considered a different aspect of emotional expression in a Latin American culture, known anecdotally as being more expressive than European cultures. Also, it may be argued that a different factor structure was obtained because the authors of the original scale used PCA for factor extraction, while the current investigation employed PAF. As indicated in the methodology, PCA was not used because it inflates variance estimates. ${ }^{31}$ In any case, further analysis using PCA instead of PAF in

Table 4 - Correlations between the BES and clinical variables

\begin{tabular}{lccccc}
\hline Variable & BES factor 1 & BES factor 2 & FNES & PHQ-9 & GAD-7 \\
\hline Total BES score & $\mathbf{0 . 9 7}$ & $\mathbf{0 . 6 0}$ & $\mathbf{0 . 3 0}$ & $\mathbf{0 . 2 8}$ & $\mathbf{0 . 2 0}$ \\
BES Factor 1 & & $\mathbf{0 . 3 9}$ & $\mathbf{0 . 3 2}$ & $\mathbf{0 . 2 8}$ & $\mathbf{0 . 2 0}$ \\
BES Factor 2 & & & 0.09 & 0.13 & 0.10 \\
\hline
\end{tabular}

BES = Beliefs about Emotions Scale.

Significant results are presented in bold $(p<0.001)$ 
the current study delivered similar results, reinforcing that the two-factor structure may reflect cross-cultural differences. Internal consistency was excellent for the first factor ( $a=0.90$ ), but only acceptable for the second factor ( $a=0.53$ ), suggesting some instability for this factor. Nevertheless, a two-factor structure was the best option using the current data, with factor loadings and communalities dropping in a one-factor solution. In any case, the excellent internal consistency found for the full scale suggests that the BES can be used as a single scale.

Gender differences were found in the current study, with men showing greater endorsement of beliefs about the unacceptability of experiencing or expressing negative emotions than women, a finding that was not present in a British sample. ${ }^{11}$ This may reflect traditional gender roles and sexist values in Brazilian society, which has higher gender inequality than the UK. ${ }^{39}$ According to this view, Brazilian men would see the expression of emotions as signs of weakness or less masculine behavior, in agreement with the stereotype that women are more emotional. ${ }^{40,41}$ Ethnic differences were also found, with non-Caucasian participants - the majority being from black or mixed ethnicity - showing more perfectionist beliefs. These results cannot be accounted for by differences in anxiety or depression, since ANCOVAs with these variables did not change results. One potential explanation refers to social differences, with non-Caucasian participants more commonly being from less affluent backgrounds and having more restricted access to services in Brazil, including education, or holding more traditional beliefs. ${ }^{42}$ In agreement with that, in the current study, participants with lower educational achievement also had higher BES scores, although this difference was non-significant after covarying anxiety and depression. Similar to Rimes \& Chalder, ${ }^{11}$ there was no relationship between age and beliefs about emotion.

The relationship between beliefs about emotions and clinical variables observed in the present study is largely in agreement with previous findings, ${ }^{6,4}$ with significant positive correlations being found between BES scores and assessments of anxiety, depression and fear of negative evaluation. Correlations were weaker than in previous studies using the BES, ${ }^{11}$ particularly in the case of anxiety and depression, but this may have been caused by the use of different questionnaires to measure these constructs. The fact that these correlations are present with many variables but are not particularly strong reinforce the notion of beliefs about emotion as a "transdiagnostic vulnerability factor", 11 which contribute to a range of clinical problems.
The study also replicates previous findings linking perfectionist beliefs about emotions with fatigue. ${ }^{11,43,44}$ It has been suggested that maladaptive strategies used by people with dysfunctional beliefs may lead to increased distress, which in turn may contribute to higher levels of fatigue. ${ }^{11}$ It is also possible that increased fatigue leads to more perfectionist beliefs about emotions, for example with patients with chronic fatigue being more concerned about evaluation by others in general and fearing stigma. Future studies using an experimental design manipulating either fatigue or beliefs about emotions may help to establish the direction of causality in this case.

The current study has two main related limitations: data collection was carried out online and there was no detailed assessment of participants by a clinician. Because of that, the sample may contain patients with different disorders, leading to higher scores on the BES. Nevertheless, analysis of mean scores in the clinical scales (Table 1 ) suggests that the prevalence of psychiatric symptoms was not particularly prominent in the sample. Online data collection may have led to sampling biases, with participants with online access showing a different profile in relation to the general population. This is important to consider for future studies using the validated scale, which may opt to expand data collection to other settings. It is also possible that people respond to the BES differently if the scale is completed online in comparison to a "paper and pencil" assessment. However, previous studies using different application procedures showed similar results for the BES. ${ }^{45}$

In conclusion, the current study provides evidence that the Brazilian adaptation of the BES has solid psychometric properties, being suitable for the assessment of perfectionist beliefs about emotion. This highlights that the construct of beliefs about emotion is valid also in developing countries, allowing more studies to be conducted exploring this theme. Differences between this study and the validation of the original scale may be related to cross-cultural and contextual differences, such as more emphasis given to selfcontrol in expressive societies, traditional gender roles and inequality of access to services and information according to ethnicity and educational level. The study confirms previous associations of the BES with a number of important clinical outcomes, suggesting the need of future studies exploring the impact of these beliefs on prognosis and treatment success. Additionally, studies using an experimental approach may help to determine the direction of causality between beliefs about emotions and clinical outcomes. 


\section{Disclosure}

No conflicts of interest declared concerning the publication of this article.

\section{References}

1. Surawy C, Hackmann A, Hawton K, Sharpe M. Chronic fatigue syndrome: a cognitive approach. Behav Res Ther. 1995;33:53544.

2. Corstorphine E. Cognitive-emotional-behavioural therapy for the eating disorders: working with beliefs about emotions. Eur Eat Disord Rev. 2006;14:448-61.

3. Jack DC. Silencing the self: women and depression. Massachusetts: Harvard University Press; 1991.

4. Cramer KM, Gallant MD, Langlois MW. Self-silencing and depression in women and men: Comparative structural equation models. Pers Individ Dif. 2005;39:581-92.

5. Todarello O, Taylor GJ, Parker JD, Fanelli M. Alexithymia in essential hypertensive and psychiatric outpatients: A comparative study. J Psychosom Res. 1995;39:987-94.

6. Ali A, Toner BB, Stuckless N, Gallop R, Diamant NE, Gould MI, et al. Emotional abuse, self-blame, and self-silencing in women with irritable bowel syndrome. Psychosom Med. 2000;62:76-82.

7. Jones $M$, Wessinger $S$, Crowell $M$. Coping strategies and interpersonal support in patients with irritable bowel syndrome and inflammatory bowel disease. Clin Gastroenterol Hepatol. 2006;4:474-81.

8. Fox H, Hong K, Sinha R. Difficulties in emotion regulation and impulse control in recently abstinent alcoholics compared with social drinkers. Addict Behav. 2008;33:388-94.

9. Nock MK, Mendes WB. Physiological arousal, distress tolerance, and social problem-solving deficits among adolescent selfinjurers. $\square$ J Consult Clin Psychol. 2008;76:28-38.

10. Hambrook D, Oldershaw A, Rimes K, Schmidt U, Tchanturia K, Treasure J, et al. Emotional expression, self-silencing, and distress tolerance in anorexia nervosa and chronic fatigue syndrome. $\mathrm{Br}$ J Clin Psychol. 2011;50:310-25.

11. Rimes KA, Chalder T. The Beliefs about Emotions Scale: Validity, reliability and sensitivity to change. J Psychosom Res. 2010;68:285-92

12. Veilleux JC, Salomaa AC, Shaver JA, Zielinski MJ, Pollert GA. Multidimensional assessment of beliefs about emotion. Assessment. 2015;22:86-100.

13. Tamir M, John OP, Srivastava S, Gross JJ. Implicit theories of emotion: Affective and social outcomes across a major life transition. J Pers Soc Psychol. 2007;92:731-44.

14. Ekman P. Basic emotions. In: Dalgleish T, Power M. Handbook of cognition and emotion. Malden: Wiley Interscience; 2005. p. 30120.

15. Matsumoto D. Cultural similarities and differences in display rules. Motiv Emot. 1990;14:195-214.

16. Shaver $\mathrm{P}, \mathrm{Wu} \mathrm{S}$, Schwartz J. Cross-cultural similarities and differences in emotion and its representation: A prototype approach. Pers Soc Psychol Rev. 1992;13:175-212.

17. Zborowski M. Cultural components in responses to pain. J Soc Issues. 1952;8:16-30.

18. Zola IK. Culture and symptoms--An analysis of patients presenting complaints. Am Sociol Rev. 1966;31:615-30.

19. Savani K, Kumar S, Naidu NVR, Dweck CS. Beliefs about emotional residue: The idea that emotions leave a trace in the physical environment. J Pers Soc Psychol. 2011;101:684-701.

20. Brislin RW. Back-translation for cross-cultural research. J Cross Cult Psychol. 1970;1:185-216.

21. Kroenke K, Spitzer R., Williams J, Monahan P, Löwe B. Anxiety disorders in primary care: prevalence, impairment, comorbidity, and detection. Ann Intern Med 2007;146:317-25.

22. Spitzer RL, Kroenke K, Williams JBW, Löwe B. A brief measure for assessing Generalized Anxiety Disorder. Arch Intern Med. 2006;166:1092.
23. Mapi Research Institute. Certificate of linguistic validation certificate: general anxiety disorder-7 (GAD-7). Lyon: Map Research Institute; 2006.

24. Kroenke K, Spitzer RL, Williams JBW. The PHQ-9. J Gen Intern Med. 2001;16:606-13.

25. Osório FCADL, Mendes AV, Crippa JA, Loureiro SR. Study of the discriminative validity of the $\mathrm{PHQ}-9$ and $\mathrm{PHQ}-2$ in a sample of Brazilian women in the context of primary health care. Perspect Psychiatr Care. 2009;45:216-27.

26. Chalder T, Berelowitz G, Pawlikowska T, Watts L, Wessely S, Wright, Wallace E. Development of a fatigue scale. J Psychosom Res. 1993;37:147-53.

27. Cho HJ, Costa E, Menezes PR, Chalder T, Bhugra D, Wessely S. Cross-cultural validation of the Chalder Fatigue Questionnaire in Brazilian primary care. J Psychosom Res. 2007;62:301-4.

28. Watson D, Friend R. Measurement of social-evaluative anxiety. $\square$ J Consult Clin Psychol. 1969;33:448-57.

29. Silva A, Nardi A. Translation and cross-cultural adaptation of the Brazilian Portuguese version of the Fear of Negative Evaluation Scale (FNE). Rev Psiquiatr Rio Gd Sul. 2009;31:159-69.

30. Tabachnick B, Fidell L. Using multivariate statistics. 4th ed. London: Pearson; 2001.

31. Costello A, Osborne J. Best practices in exploratory factor analysis: four recommendations for getting the most from your analysis. Pract Assess Res Eval. 2005;10 [cited 10 Aug 2017]. http://pareonline.net/pdf/v10n7.pdf

32. Hayton J, Allen D, Scarpello V. Factor retention decisions in exploratory factor analysis: a tutorial on parallel analysis. Organ Res Meth. 2004;7:191-205.

33. O'Connor B. SPSS and SAS programs for determining the number of components using parallel analysis and Velicer's MAP test. Behav Res Methods Instrum Comput. 2000;32:396-402.

34. Matsunaga M. How to factor-analyze your data right: Do's, don'ts, and how-to's. Int J Psychol Res. 2010;3:97-110.

35. Jason L, Evans JM, Brown M, Porter N, Brown A, Hunnell J, et al. Fatigue scales and chronic fatigue syndrome: issues of sensitivity and specificity. Disabil Stud Q. 2011;31. pii: 1375

36. George D, Mallery P. SPSS for Windows step by step: a simple guide and reference, 11.0 update. Boston: A \& B; 2003

37. Brown TA. Confirmatory factor analysis for applied research. New York: Guilford Press; 2006.

38. Hatcher L. A step-by step approach to using the SAS system for factor analysis and structural equation modeling. Cary: SAS Institute; 1994.

39. World Economic Forum. The global gender gap report. Geneva: World Economic Forum; 2014. [cited 10 Aug 2017]. http://www3. weforum.org/docs/GGGR14/GGGR CompleteReport 2014.pdf

40. Timmers $M$, Fischer $A$, Manstead $\bar{A}$. Ability versus vulnerability: Beliefs about men's and women's emotional behaviour. Cogn Emot. 2003;17:41-63.

41. Brody R, Hall JA. Gender and emotion in context. In: Lewis M, Haviland-Jones J, Barrett $L$, editors. Handbook of emotions. 3rd ed. New York: Guilford; 2008. p. 395-408.

42. Pagano A. Everyday narratives on race and health in Brazil. Med Anthropol Q. 2014;28:221-41.

43. Kempke S, Luyten P, Claes S, Goossens L, Bekaert P, Wambeke $P V$, et al. Self-critical perfectionism and its relationship to fatigue and pain in the daily flow of life in patients with chronic fatigue syndrome. Psychol Med. 2013;43:995-1002.

44. Flo $E$, Chalder T. Prevalence and predictors of recovery from chronic fatigue syndrome in a routine clinical practice. Behav Res Ther. 2014;63:1-8.

45. James K, Verplanken B, Rimes KA. Self-criticism as a mediator in the relationship between unhealthy perfectionism and distress. Pers Individ Dif. 2015;79:123-8.

\section{Correspondence:}

Daniel C. Mograbi

Institute of Psychiatry, Psychology and Neuroscience, King's College London

PO Box 078, De Crespigny Park

SE5 8AF - London - UK

Tel.: +44 (20) 78485718

E-mail: daniel.mograbi@kcl.ac.uk 


\section{Appendix 1}

\section{Brazilian version of the Beliefs about Emotions Scale}

Por favor marque a coluna que melhor descreve como você pensa. Note que, porque as pessoas são diferentes, não há resposta certa ou errada para estas afirmações. Para decidir se uma resposta é típica do seu jeito de ver a vida, considere simplesmente como você pensa na maior parte do tempo.

\begin{tabular}{|c|c|c|c|c|c|c|c|}
\hline & $\begin{array}{l}\text { Concordo } \\
\text { totalmente }\end{array}$ & \begin{tabular}{|c|c|}
$\begin{array}{c}\text { Concordo } \\
\text { muito }\end{array}$ \\
\end{tabular} & $\begin{array}{c}\text { Concordo } \\
\text { parcialmente }\end{array}$ & Neutro & $\begin{array}{c}\text { Discordo } \\
\text { parcialmente }\end{array}$ & $\begin{array}{l}\text { Discordo } \\
\text { muito }\end{array}$ & $\begin{array}{l}\text { Discordo } \\
\text { totalmente }\end{array}$ \\
\hline \multicolumn{8}{|l|}{$\begin{array}{l}\text { É um sinal de fraqueza se eu tenho } \\
\text { pensamentos tristes. }\end{array}$} \\
\hline \multicolumn{8}{|l|}{$\begin{array}{l}\text { Se eu tenho dificuldades, não devo admiti- } \\
\text { las para os outros. }\end{array}$} \\
\hline \multicolumn{8}{|l|}{$\begin{array}{l}\text { Se eu perder controle das minhas emoções } \\
\text { na frente dos outros, eles vão me achar } \\
\text { uma pessoa inferior. }\end{array}$} \\
\hline \multicolumn{8}{|l|}{$\begin{array}{l}\text { Eu deveria ser capaz de controlar minhas } \\
\text { emoções. }\end{array}$} \\
\hline \multicolumn{8}{|l|}{$\begin{array}{l}\text { Se eu estou tendo dificuldades, é } \\
\text { importante fingir que está tudo bem. }\end{array}$} \\
\hline \multicolumn{8}{|l|}{$\begin{array}{l}\text { Se eu mostrar sinais de fraqueza, os outros } \\
\text { irão me rejeitar. }\end{array}$} \\
\hline \multicolumn{8}{|l|}{$\begin{array}{l}\text { Eu não devo me deixar levar por } \\
\text { sentimentos negativos. }\end{array}$} \\
\hline \multicolumn{8}{|l|}{$\begin{array}{l}\text { Eu deveria ser capaz de lidar sozinho com } \\
\text { dificuldades, sem contar com os outros } \\
\text { para ajuda. }\end{array}$} \\
\hline \multicolumn{8}{|l|}{$\begin{array}{l}\text { Para ser aceito pelos outros, eu devo } \\
\text { guardar quaisquer dificuldades ou } \\
\text { sentimentos negativos para mim mesmo. }\end{array}$} \\
\hline \multicolumn{8}{|l|}{ É idiotice ter pensamentos tristes. } \\
\hline \multicolumn{8}{|l|}{$\begin{array}{l}\text { Seria um sinal de fraqueza mostrar minhas } \\
\text { emoções em público. }\end{array}$} \\
\hline $\begin{array}{l}\text { Outros esperam que eu sempre esteja no } \\
\text { controle de minhas emoções. }\end{array}$ & & & & & & & \\
\hline
\end{tabular}

